\title{
Social and Cultural Dimensions of Digital Inclusions.
}

\author{
Dr. Juan Luis Chulilla, CEO of OnLine and OffLine
}

\begin{abstract}
The state of Internet Adoption Curve in 2011 for the developed countries reveals an apparently optimistic picture: the majority of European and North American populations have adopted main online tools and resources. However, as access of the majority of these populations doesn't mean universal access, we review some of the main proposals about Digital Divide and the use of EU Digital inclusion perspective in order to focus on the main obstacles for universal access to Internet.
\end{abstract}

Palabras clave - Cultural and Social Dimensions of Digital Divide, Digital Divide, Digital Inclusion, Internet Adoption Curve.

\section{INTRODUCTION}

$\mathrm{D}$ gital Inclusion is one of the most important strategic policies of the European Union, as it is mentioned in a 10-year series of Programs - the last one is the Communication from the commission to the european parliament, the council, the european economic and social committee and the committee of the regions: A Digital Agenda for Europe [10]. The most brilliant aspect of this concept (as opposed to other related concepts such as Digital Divide) is that Digital Inclusion encompasses both the problem and its solution:

- There are population profiles (persons with disabilities, homeless people, etc.) which suffer different grades and aspects of social exclusion.

- The progress on adoption curve of Internet is such that nowadays online technologies are essential for different dimensions of citizens' quality of life, opportunities and personal development. Individuals who lack an appropriate level of digital inclusion suffer not only digital exclusion but actual social exclusion too.

- People experiencing social exclusion more often suffer a situation of digital exclusion. In addition, for these individuals digital exclusion and social exclusion feed back each other and each contributes to maintaining the other one.

- However, digital inclusion is not only a strong benefit in itself but an efficient ally in overcoming the various aspects of social exclusion, from personal (communication and the like) to professional and citizenship.

\section{DIGITAL DIVIDE, SOLVED?}

It is very suggestive that this concept, so operative, is not very mentioned and used outside of research programs related with European Union policies. Its impact in the population is clearly negligible, specially when we compare it with the "tradicional" concept, digital divide. Without fear of doublequote-abusing, "traditionally" Digital Divide its a capability knife which parts societies and the entire World in two: having and not having people.

Until some years ago, it was cristal-clear: some people have access to computers and Internet connection, some haven't. Some people have the skills and knowledges needed not only for Internet access, but for obtaining significant benefits from it. Because of it, both public and private institutions invested a lot of resources and efforts in fighting against what was perceived as a severe social problem. Compaine [1] focused a provocative piece of work denouncing the excesses which were being committed fighting against digital divide. He sustained that Digital divide was being clearly exaggerated in 2001 (yes, in 2001) and was at least in part a believe more than a fact. Therefore, the so-called problem was going to be solved by itself, just with time, and public intervention was not needed nor justified.

Such extreme position was clearly nor acceptable at that time. Even in America, digital inclusion was far from solved don't even mention the rest of the developed countries. Let's remember that this statement was made four years before O'Reilly [4] definition and launch of Web 2.0. Maybe Compaine was right about Digital divide, but not with the date. Is digital divide solved in 2011 ?

\section{DIGITAL DIVIDE AND SOCIAL INCLUSION}

As we can see with the sucession of European Union programs, not in its absolute sense. Reducted to absurd, if Digital Inclusion was solved, more and more public programs were not needed. However, Digital divide is not a popular concept anymore. Maybe Compaine is socially right. Concern for digital divide matters to very few people. As Internet adoption curve has progressed and it has reached late majority stage, it seems to be more and more clear that, as Internet has 
been accepted in a majority of companies and homes, digital divide is not a problem anymore... in the developed world. And, of course, in the underdeveloped world, (<irony>) Digital divide is not a problem compared with hunger $(</$ irony $>)$.

Fortunately, other authors have not lost respect for the digital divide and, on the contrary, they point out different dynamics which show clearly that this is an ongoing problem. Warschauer, stresses $[7,8]$ the urgent need to abandon the idea of one-dimensional and binary digital divide in order to adopt a multidimensional concept and gradual. In 2011, a binary concept is completely unacceptable and is disconnected from reality; however, the concept of digital divide is strongly connected to a binary meaning. Norris [3] remarks that, without intervention, digital divide is going to deepen and is going to reinforce social exclusion too taken its solution for granted is a very good recipy for social disaster. Van Dijk $[5,6]$ points out a growing paradox: although physical access can be taken for granted more and more, it happens almost the opposite with the knowledge and benefits derived from Internet use. Van Dijk connect this paradox with Matthew effect [2], in the sense that the more knowledge someone has, the easier for him to obtain more.

Although the works cited above were written some years ago, their base is maintained. Indeed, all of them are pointing several aspects of digital inclusion related with the beliefs of societies about technology, or how other beliefs obscures some facts about the reality of digital inclusion.

Internet adoption curve is a fact. There can be used a lot of different metrics in order to define in which point of the curve are our societies now, but there is no discussion about the basic stage: in all the developed world, we have surpassed the early majority. This situation has a result: Internet access and use is taken for granted. Therefore, digital inclusion is not a very visible problem. As citizens of democracies, it should be mandatory to conceive Internet as an universal service and even right, so even if a small minority of the population is digitally excluded, this is a problem.

Anyways, the lack of visibility of Digital Inclusion is a cultural trend. This is only of the many cultural trends that affects Internet usage in a very significant way. As Internet has been integrated in the very core of our societies, is not a neutral technology anymore. People have make the internet full of different meanings and values, some of them positives and some not. A good set of the negative values related to the Internet are very influent because they are very and not easy to detect lack of visibility of digital divide is a good example.

In 2004, Warschauer proposes [8] a conceptual mark for good and efficient Digital Inclusion policies in which cultural factor have a strong role. It's painfully clear and simple: any local or sectorial initiative oriented to improve Digital
Inclusion is unlikely to succeed without taking into account basic cultural trends of each specific group. If it's not paid attention to active involvement of people, if beliefs and practices related with technology are not taking into consideration, the initiative won't answer actual needings.

\section{AN ANNOUNCEMENT}

In www.emadrid2011.es, we are going to publish a 18 month long ethnographic research about social and cultural dimensions of Digital Inclusion and a complete methodology and good practices in order to encourage the groups, collectives and associations to help themselves to improve their digital empowerment. We have detected a good number of social and cultural trends which strongly influence the digital inclusion of collectives. The results are going to be published in the 2nd quarter of 2011, and we sincerelly hope that the monography will encourage other researchers to improve the knowledge about this essential problem.

\section{V.REFERENCES}

[1] Compaine, B. (2001).The digital divide: facing a crisis or creating a myth? . The MIT Press

[2] Merton, R. (1968). "The matthew effect in science". Science, 159 (3810), 56.

[3] Norris, P. (2001). Digital divide: Civic engagement, information poverty, and the Internet worldwide. Cambridge, Ma: Cambridge Univ Pr.

[4] O'Reilly, T. (2005). What is web 2.0. design patterns and business models for the next generation of software. Disponible en http://oreilly.com/web2/ archive/what-is-web-20.html

[5] Van Dijk, J. (2005). The deepening divide: Inequality in the information society. Thousand Oaks, CA: Sage Publications.

[6] Van Dijk, J., and Hacker, K. (2003). "The digital divide as a complex and dynamic phenomenon". The information society, 19 (4), 315-326.

[7] Warschauer, M. (2002). "Reconceptualizing the digital divide". First Monday, 7 (7-1).

[8] Warschauer, M. (2004). Technology and social inclusion: Rethinking the digital divide. Cambridge, MA: MIT Press.

[9] Warschauer, M., Knobel, M., and Stone, L. (2004). Technology and equity in schooling: Deconstructing the digital divide. Educational Policy, 18 (4), 562- 588. 3

[10] Digital Agenda of Europe. http://ec.europa.eu/information society/digital-agenda/index_en.htm. 